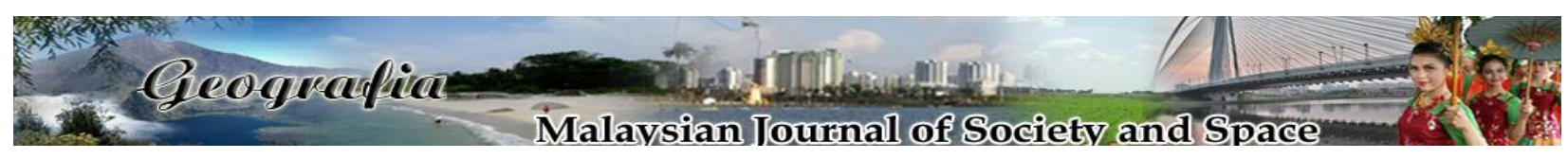

\title{
Vulnerability framework of tourism to natural disasters
}

\author{
Ak. Mohd Rafiq Ak. Matusin ${ }^{1,2}$, Chamhuri Siwar², Sharina Abdul Halim² \\ ${ }^{1}$ Faculty of Built Environment and Surveying, Universiti Teknologi Malaysia (UTM) \\ ${ }^{2}$ Institute for Environment and Development (LESTARI), Universiti Kebangsaan Malaysia \\ Correspondence: Ak. Mohd Rafiq Bin Ak. Matusin (Email: akmdrafiq@gmail.com)
}

Received: 21 March 2019; Accepted: 11 August 2019; Published: 25 November 2019

\begin{abstract}
Natural disaster is a major challenge to tourism destinations. Thus, a vulnerability analysis is required as a part of disaster risk reduction to ensure their sustainability. This study aimed to present an analysis of the tourism vulnerability framework for those areas that face natural prone disasters. To achieve the study purpose, the framework was developed through a review of research papers that focusing on the application of vulnerability approach in sustainable tourism discourse. The search databases used for literature review including Google Scholar, SCOPUS and Science Direct. The primary result is discussed using the constructs of Vulnerability Framework for Sustainable Tourism Development (VFSTD), which composed of several elements: shocks-stressors, exposure, sensitivity and system adaptiveness. The VFSTF is fundamentally adopted from Turner Vulnerability Analysis in Sustainability Science, which highlights the integration of vulnerability approach and sustainability science as a system. For tourism as a core, VFSTD would helpful in clarifying the fundamental of vulnerability analysis and enhancing the effectiveness of risk reduction action for tourism in disaster-prone areas. Particularly, users of VFSTD would able to explore the factors and processes that create and perpetuate vulnerability to natural disasters in tourism destinations and elicit adjustment and feedback to encourage tourism sustainability more holistically.
\end{abstract}

Keywords: conceptual framework, natural disaster, sustainable tourism, tourism destination, tourism vulnerability, vulnerability analysis

\section{Introduction}

Tourism industry has been globally expanding year-on-year and has become one of the drivers for economic development in many countries. As per United Nation World Tourism Organization (2018), the arrivals of international tourists increased worldwide in 2017 by $7 \%$ to 1,322 million and this momentum is expected to continue in 2018 at a rate of $4-5 \%$. To support the tourists' demands, they allow access to extreme and fragile natural environments that 
potentially offer spectacular attractions to tourists. For instance, mountainous areas are an increasingly popular tourism destination for tourists because of their magnificent biophysical characteristics. Jodha (1991) discussed the specificities of mountainous areas including inaccessibility, fragility, marginality, diversity, and ecological niches, which these characteristics of mountainous areas acted as both notable attractions and hindrances for nature-based tourism (Nyaupane \& Chhetri, 2009).

Natural disasters (i.e. earthquakes, volcanic eruptions, tsunamis, hurricanes, etc.) are unavoidable and uncertain which their impacts on tourism particularly nature-based destinations are violent and severe (Kato, 2017; Fukao, 2015; Orchiston, 2013; Tsai \& Chen, 2010; Sutherland et al., 2007; Prideaux, 2003). Tourism is vulnerable to natural disasters because of the business' lack of preparedness and knowledge as well as inadequate location-based hazard and vulnerability assessments (Le Masson \& Kelman, 2011) and tourism's limited integration with national disaster management systems (Hystad \& Keller, 2008; Faulkner 2001). Simpson and Gladin (2008) indicated that incentives could be required to promote good practice in Disaster Risk Reduction (DRR) amongst tourism operators. Recently, the focus shifted from that of reactive response measures to a comprehensive, participatory and proactive disaster planning (Innocenti \& Albrito, 2011).

Consequently, a comprehensive action plan for tourism operations during natural disasters is critical to ensure its viability and sustainability. For that purpose, one of the important preparatory steps of disaster management for sustainable development is vulnerability assessment (Adger, 2006). There are certain vulnerability frameworks that particularly focus on global environmental change (see IPCC, 2007; Smit \& Wandel, 2006; Birkmann, 2006; Adger, 2006; Brooks, 2003; Turner et al., 2003; Holling \& Gunderson, 2002; McCarthy et al., 2001), which have later been applied for disaster-related research that assesses the vulnerability of the system affected. Therefore, the principal question is as follows: How to incorporate a vulnerability analysis in tourism to maintain its sustainability facing the disasters? In this paper, we present an analysis of vulnerability framework of natural disasters specifically in the context of tourism.

\section{Literature review}

In the context of hazards, vulnerability is the extent to which a community, system, or asset can be susceptible to damage caused by the hazard (UNISDR, 2012). While Turner et al. (2003) presented the Turner's Vulnerability Analysis for Sustainability Science, TVASS (Figure 1), which was aimed at consistently framing vulnerability analysis for research in both sustainability science and global environmental change. Specifically, TVASS's adoption for identifying vulnerabilities of a tourist destination has been confirmed, including its dynamism and differential nature of vulnerability in which populations, characteristics and driving forces of vulnerability changed over space and time (Vogel \& O'Brien, 2004), all of which help acknowledge various post-events feedbacks of vulnerability back into the system. Moreover, TVASS recognises that an individual's or group's exposure, sensitivity and resilience to shocks is directly linked to access and entitlements towards resources at a given location as well as places they experience in a wider context (Calgaro \& Lloyd, 2008). This allows the determination of factors and processes that influence a subject's vulnerability over time and place 
TVASS framework is based on two archetypal reduced-form models that discussed vulnerability analysis: Risk-Hazard (RH) and Pressure-and-Release (PAR) models (Turner et al., 2003). Burton et al. (1978) and Kates (1985) used the RH model to understand the impact of hazard as a function of exposure to the event and dose-response (sensitivity) of the entity that was exposed. On the other hand, the PAR model was explicitly a function of the perturbation, stressor, or stress related to the vulnerability of the exposed unit (Blaikie et al., 1994). Importantly, the development of vulnerability analysis depicts three major concepts: entitlement, coping through diversity and resilience (Kasperson et al., 2012). These concepts were deliberately adopted in Turner's vulnerability framework in the context of exposure, sensitivity and resilience.

Consequently, TVASS helps identify the following elements for vulnerability analysis which are specifically aimed at advancing sustainability: (i) multiple interacting perturbations and stressors/stresses, (ii) exposure beyond a perturbation and stressor/stress's presence, (iii) sensitivity of a coupled system to exposure, (iv) a system's capacity to cope or respond (resilience), (v) adjustments/adaptations (system's restructuring after responses are considered), and (vi) nested scales and scalar dynamic of hazards, coupled systems as well as their responses (Turner et al., 2003). Note that the identified elements are predicated through synergy between human and biophysical subsystems, which both are rooted towards sustainability. In turn, drive Turner's vulnerability framework's coherent goals towards sustainability.

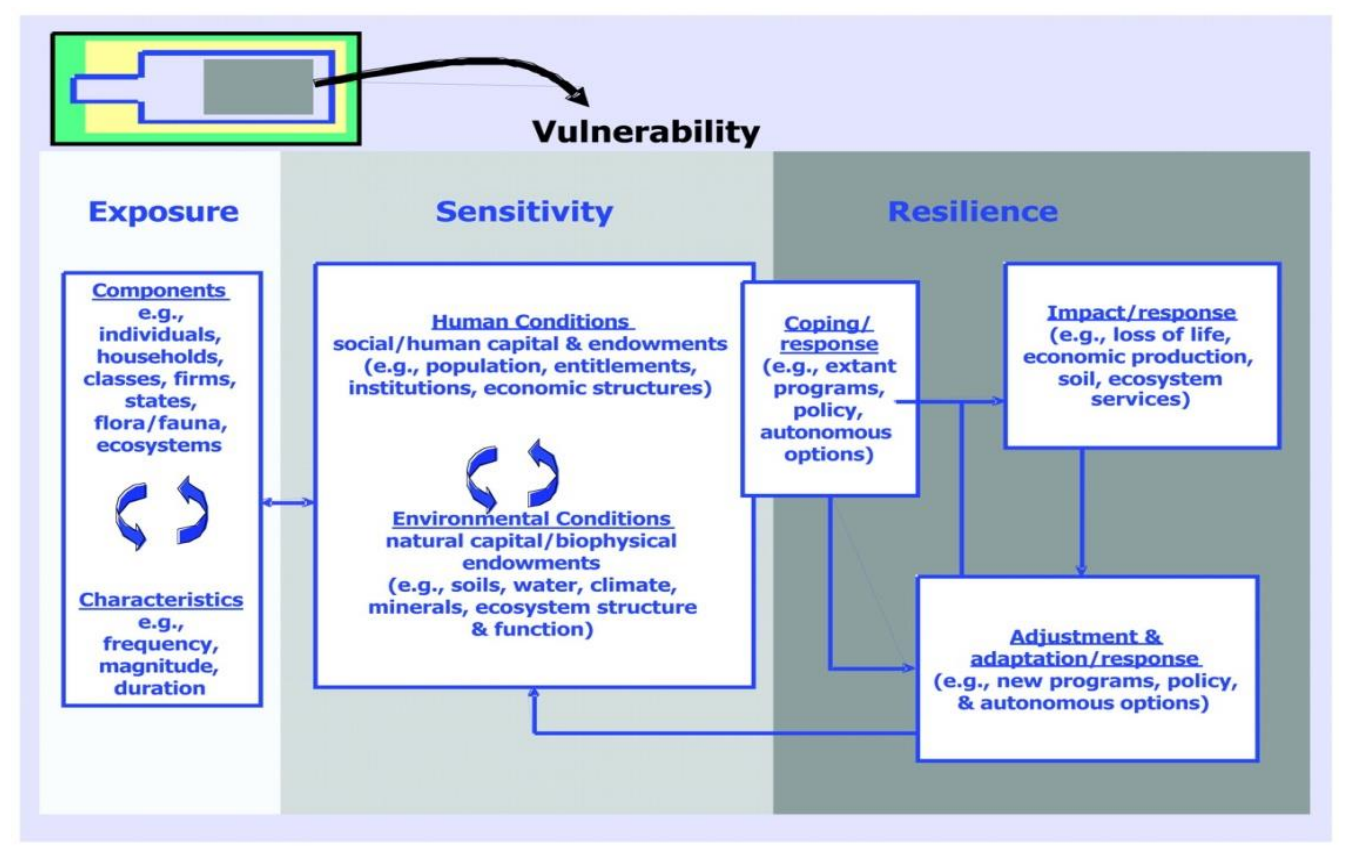

Source: Turner et al., 2003

Figure 1. Turner's Vulnerability analysis for sustainability science (TVASS)

Furthermore, Turner et al. (2003) emphasised the basic architecture for the vulnerability analysis framework: $(i)$ linkages to a broader human and environment conditions and processes that operate on the coupled system, (ii) perturbations and stressors/stress emerging from these conditions and processes, and (iii) coupled human-environment system of concern in which the vulnerability exists such as exposure and responses (coping, impacts, adjustments and 
adaptations). Note that all the elements are interactive and scale dependent; therefore, the hazards arose from external and internal influences because of their complexity, nonlinearity and place-based systems. Furthermore, the sensitivity was commonly determined via humanenvironment conditions of the system (which considers effects of the coping mechanism as well as impacts of the experienced exposure). Collectively, the outcomes would help determine the system's resilience and effect of other scalar dimensions of the problem (Turner et al., 2003).

Specifically, TVASS has been highlighted as the fundamental vulnerability analysis within tourism vulnerability frameworks for disasters such as (i) Sustainability Vulnerability Framework, SVF (Calgaro \& Lloyd, 2008); (ii) Destination Sustainability Framework, DSF (Calgaro et al. 2014); and (iii) Tourism Disaster Vulnerability Framework, TDVF (Becken et al., 2014).

\section{i. Sustainability Vulnerability Framework (SVF)}

Calgaro and Lloyd (2008) constructed the Sustainability Vulnerability Framework (SVF) (Figure 2), which is structurally quite similar with the original of Turner's framework. However, the difference lies in certain additional features of geographical concepts of relational scale and place in each component of vulnerability frameworks to expose the underlying socio-political processes and to fulfil analytical requirements that analyse various social actors that use scaled socio-political processes and structures (Calgaro \& Lloyd, 2008). Therefore, SVF is able to explore the socio-political and environmental factors that trigger a tourism destination's vulnerability.

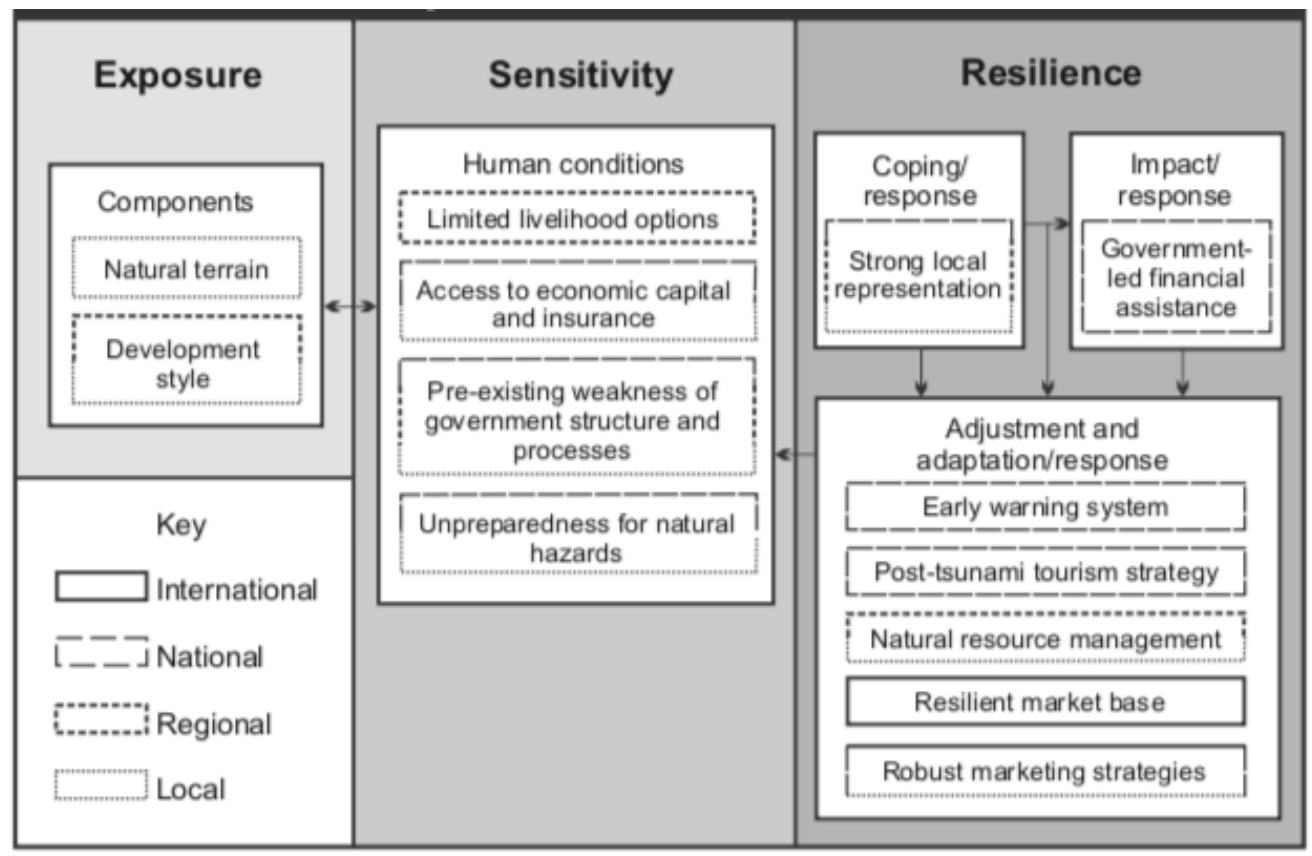

Source: Calgaro \& Lloyd, 2008

Figure 2. Sustainability Vulnerability Framework 


\section{ii. Destination Sustainability Framework (DSF)}

Calgaro et al. (2014) provided an improved Destination Sustainability Framework (DSF) (Figure 3 ) that encapsulated six elements of vulnerability along with the additional combination concept of System Approach. Purposely, DSF was used to guide the identification and analysis of factors and processes that created and perpetuated vulnerability of tourism destinations and identify factors for resilience along with social actors and agenda that could drive both action and nonaction (Calgaro et al., 2014). Therefore, DSF creates entry points and opportunities for adjustment and changes to the system (tourism destination). Similar to SVF, DSF applies geographical concepts of relational scale and place along with the additional element of time to overcome hierarchical notions of scaled actions and processes, which can shape destinations and their vulnerability levels over space and time (Calgaro et al., 2014). Moreover, DSF applies specific primary factors to shape each dimension of vulnerability and provide researchers with an analytical focal point. However, these factors are not rigid; they are rather of the malleable form and based on the type of event that destabilises the system, as well as are characterised by the type of places (destinations) and population that is affected, in addition to the focus of research questions (Calgaro et al., 2014).

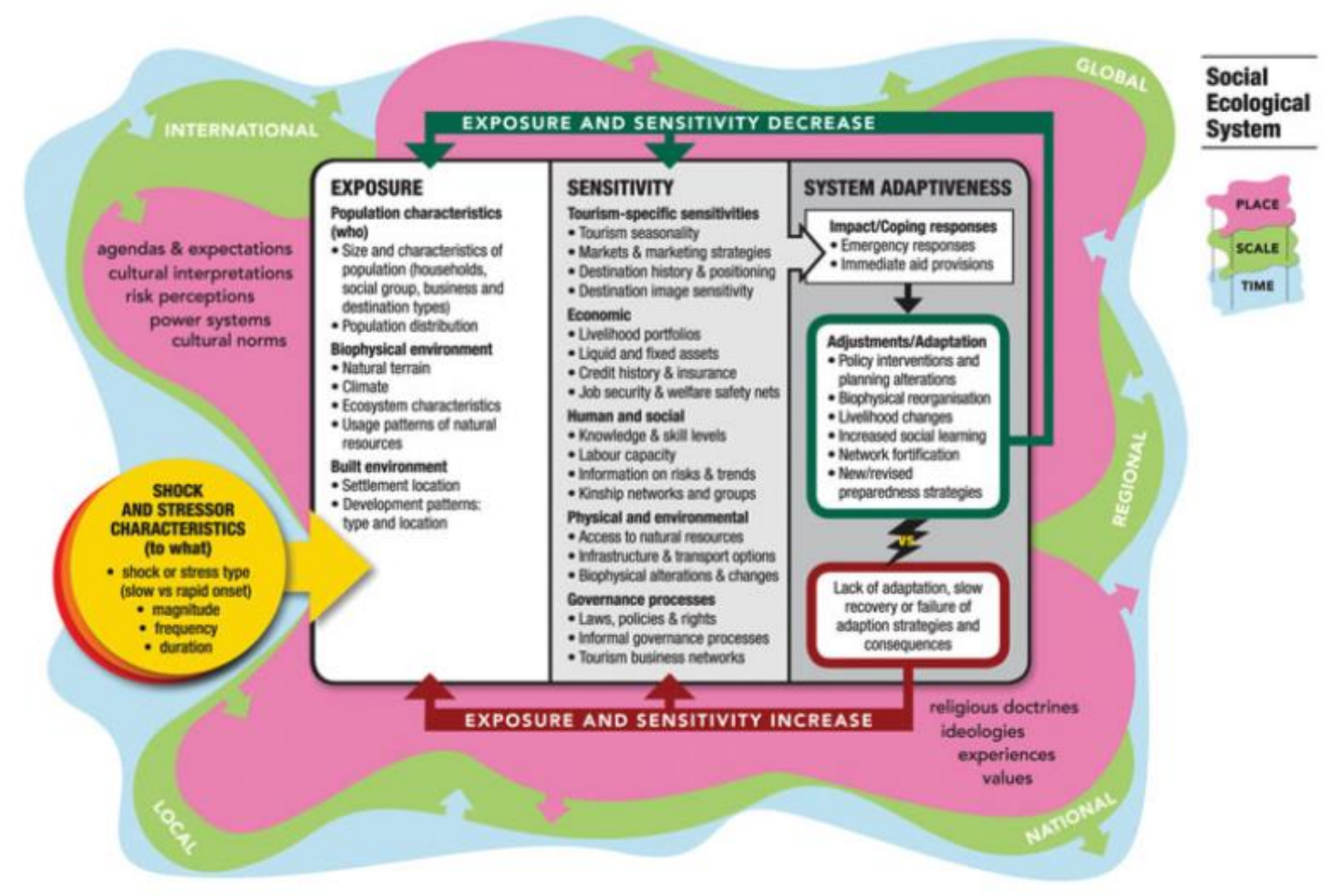

Source: Calgaro et al. 2014

Figure 3. Destination Vulnerability Framework

\section{iii. Tourism Disaster Vulnerability Framework (TDVF)}

Becken et al. (2014) discussed the Tourism Disaster Vulnerability Framework (TDVF) (Figure 4), which was empirically scrutinised to explore several tourist destinations' vulnerabilities 
towards various disasters in the Caribbean, South Pacific and Indian Ocean. Interestingly, TDVF employed Prevention, Preparedness, Response, Recovery (PPRR) measures into adaptation element of vulnerability analysis to categorise various types of measures that can be taken without ignoring the structuralist or political ecological paradigms of vulnerability. In this manner, information on DRR activities that were undertaken could be acquired. TDVF, on the other hand, merges the original elements of the Turner framework, such as exposure and sensitivity, into one vulnerability section without losing out on their importance (Becken et al., 2014).

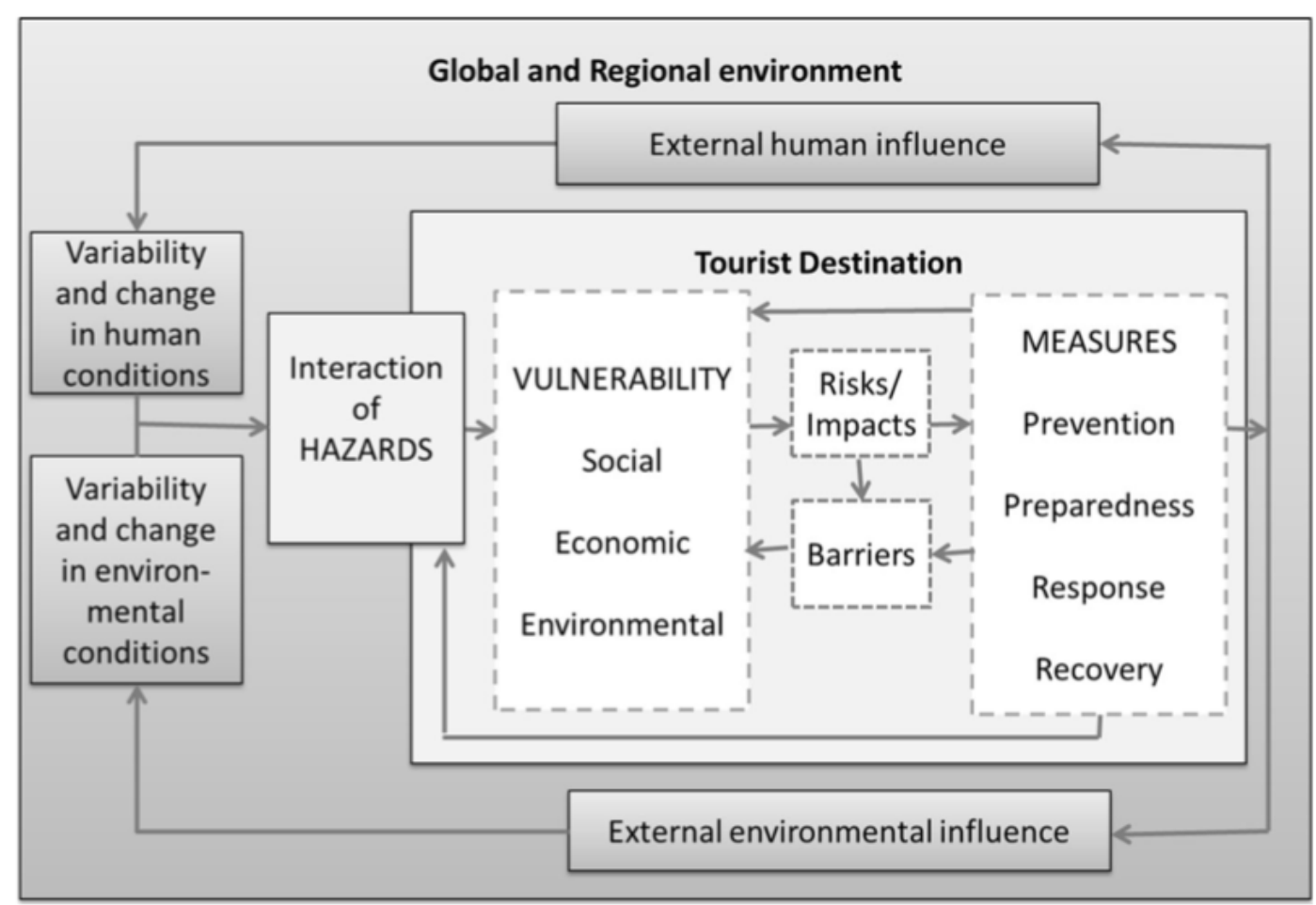

Source: Becken et al., 2014

Figure 4. Tourism Disaster Vulnerability Framework

To summarise, these three Turner-applied frameworks in tourism vulnerability to disasters have demonstrated that each framework adds value and richness to the concepts of tourism vulnerability framework. However, those frameworks are lacking to construct a detailed-on interaction of human-environment relationship in their framework. As the human-environement relationship is a core driver of sustainability science (Kates et al., 2001; Raven, 2002), while the vulnerability is a central element in the human-environment system and for research in sustainability science (Kasperson \& Kasperson, 2001). Thus, emphasization of this interaction in a vulnerability analysis would helped to build our understanding of the human-environment relationship with the objective to meet the society's requirements while sustaining various life support systems (Turner et al. 2003b), as the tourism also has no exception to bear this humanenvironment interaction in their system. Therefore, the objective of this paper is to incorporate the element of human-environment interaction into the vulnerability analysis framework of 
tourism to fill the gap by adopting the TVASS as a fundamental framework to construct the proposed framework. Importantly, TVASS builds on progress using the concept sustainability science (as the goal) and can be usefully modified by borrowing from other vulnerability frameworks to better match the focus provided by DRR (Becken et al., 2014).

\section{Methodology}

To execute the objective, a review of the literature has been conducted with the aim to establish a comprehensive framework of Vulnerability Framework for Sustainable Tourism Development (VFSTD) comprising several dimensions that providing the useful guide to analyse the tourism vulnerability in more nuance insight. To review the literature, different scientific papers reference to vulnerability approach and sustainable tourism development from different academic databases were analysed - this including Google Scholar, SCOPUS and Science Direct databases. These databases are used to encourage wide searching activities of related research papers.

\section{Results and discussion}

Vulnerability Framework for Sustainable Tourism Development (VFSTD)

Accordingly, there are four basic elements constructed in VFSTD (Figure 5), namely: (i) shocksstressors, (ii) exposure, (iii) sensitivity and (iv) system adaptiveness. The VFSTD approach is aimed to determine the vulnerability of a tourism destination affected by a natural disaster or hazard towards sustainability. Importantly, the VFSTD adds suggestions for features in each element that can be used to provide users with focus lanes regarding vulnerability in tourism context. However, the listed features are not rigid, but malleable, changeable and are based on the type of destabilising event, the destination characteristics, unit analysis and the focus of research questions.

\section{a. Shocks-Stressors Element}

The shocks-stressors element (the event that destabilises the system) is the starting point of VFSTD. As noted, the shocks-stressors element itself does not cause the vulnerability; rather, it acts as the trigger that reveals vulnerability and influences the impact on the system over space and time (Wisner et al., 2004). Conceptually, there is a subtle distinction between shocks and stressors. According to Calgaro et al. (2014), shocks are rapid onset events (terrorist acts, natural disasters, health epidemics) and unanticipated events in terms of the frequency, size and form of these events. Stressors are slow-onset events and are commonly manifestations of the interactions between humans and their environment that places increasing pressure on a localised system over time. Examples include climate change, a rise in sea level, water shortages, environmental degradation and economic downturns. It is also important to highlight that both types may take place either at a destination, near a destination, or even removed from the destination (e.g. regional events), although both types have the potential to disrupt the flow of tourists (Calgaro et al., 2014). Consequently, a resource-based community needs to respond 
effectively to each different type of shocks or stressor, which may slowly culminate in circumstances that can overwhelm the system (Cutter, 2003). To deal with it, and respond to the compound effects of multiple shocks and stressors on the flow of tourists, is a constant challenge for tourism destinations (Biggs, 2011). Therefore, VFSTD is sensitive to multi-hazards and can accommodate multiple and overlapping shocks and/or stressors in the framework analysis (pictured as red circle).

\section{The Body of VFSTD}

Vulnerability to a hazard is expressed by the factors of exposure, sensitivity and adaptive capacity (Yusuf \& Francisco, 2009). Adger (2006) also stressed that vulnerability is conceptualised as a combination of components that include exposure and sensitivity to perturbations or external stresses and the capacity of a system to adapt. Thus, the VFSTD's foundation of interconnected elements, composed of exposure, sensitivity and system adaptiveness which form the body of VFSTD. Importantly, the significant features added to the body of VFSTD are the incorporation of the element of Power and Sources, as the fulfillment of the gap and representing the human-environment relationship. Conceptually, both elements are catalyst for vulnerability (Birkmann 2006) as the Sources are referring to the place- and systemspecific which characterised by the population (Adger, 2006), while Power is considered as social capacity used by individual, networks or organization to control or manipulate the actions (Howitt, 2001). Accordingly, VFSTD refering Sources as tourism and Power as social capital which both are contextualized as human-environment interaction that incorporated into the framework.

\section{a. Power: Social capital}

There are three main types of social capital: (i) bonding social capital, (ii) bridging social capital and (iii) linking social capital (Szreter \& Woolcock, 2004). Bonding social capital determines internal ties and the strong bonds between people who are emotionally close, such as family members and relatives (Aldrich \& Meyer, 2015; Ruiu et al., 2017; Sanyal \& Routray, 2016). Bonding social capital also refers to horizontal relationships among a network of members with similar socio-economic status, or from the same ethnic background (Putnam, 2000). A close relationship could offer social support and immediate assistance when a disaster strikes (Guo et al., 2018). Bridging social capital refers to loose, weak, external ties among heterogeneous individuals such as friends, community neighbourhoods and other tourism business operators (Guo et al., 2018). Szreter and Woolcock (2004) defined bridging social capital as the relationship among people who are distinctly dissimilar in terms of age, socio-economic status, race/ethnicity and education. This open and inclusive bridging social capital is based on common interest and is a critical factor for gathering information and lending external assistance (Agnitsch et al., 2006; Sanyal \& Routray, 2016). Linking social capital depicts connections with institutions and political structures such as non-governmental organisations (NGOs), industry associations and local tourism authorities (Guo et al., 2018). Linking social capital also presents a vertical relationship network that reflects trust in relationships with authorities and it is effective for mobilising resources and power (Poortinga, 2012; Bhandari, 2014). As highlighted feature, Social Capital defines the local social capital characteristics (bonding, bridging and linking) within the tourism community. 


\section{b. Sources: Tourism}

The tourism experience conducted by the host often characterised by environment (physical and culture) of the destination. Dregde and Jenkins (2003) explained the production of tourism products often influenced by the destination image or icon that encompasses the interaction within multi-scale of business and services including accommodation, guidance, marketing, operation and duration of the interaction. While, destructive events like natural disasters, unstable politics activities and disease outbreak have caused chaos to tourism operation which influencing tourists' perceptions towards the affected destinations (Ritchie, 2008). Thus, tourists chose to not visit the unsafe with negative image of tourism destination (Scott et al. 2008). To respond the issue, tourism operation started to implement the Natural Disaster Management (NDM) in their development. The NDM is useful in providing a preparatory response, emergency, recovery as well as long-term adjustment strategy (Faulkner, 2001). Therefore, Sources present the identity of the tourism community and its activities, including the size of the tourism business, types of products, types of activities, period of business operation and their tourism disaster management plan.

\section{c. Exposure element}

Clark et al. (2000) defined exposure as the degree to which an exposure unit (who or what) comes into contact with stressors or shocks. Exposure is also expressed as the degree of risk a system faces from natural disasters (Tsao \& Ni, 2016), an attribute of the relationship between the system and perturbation (Gallopin, 2006), as well as a product of physical location and the character of the built and natural environment (Pelling, 2003). Operationally, the shocksstressors are the contact with the exposure as the expression of the interaction of natural hazards with the tourism community, within the broader context of social capital changes.

\section{d. Sensitivity element}

Sensitivity is defined as the degree to which a community or group is affected by exposure to stresses (Clark et al., 2000) and it reflects the pre-existing capital conditions that build anticipatory and response capabilities (Pelling, 2003). It also represents limited livelihood options and seasonality (Moser et al., 2001). Sensitivity also lists similar two components abovementioned. Social capital manifests networks and connectedness, group membership, relationships, and levels of trust and reciprocity (Calgaro et al., 2014). As discussed previously, this social capital provides the ability to encourage the recovery of communities in the aftermath of disasters. However, social capital also may foster social exclusion, manifested through dominant power structures and historically embedded cultural norms (DFID, 1999).

\section{e. System Adaptiveness Element}

System adaptiveness often refers to a dynamic state in which a population or system is effective in responding to the convergence of multiple stresses. At the same time, it incorporates anticipatory actions for preparedness, short-term responses, long-term adjustment and the acknowledgment of subsequent feedback (Nelson et al., 2007). Accordingly, the final elements

of VFSTD are the system adaptiveness that comprise: (i) short-term adaptiveness (immediate 
coping responses) and (ii) long-term adaptiveness (adjustment of social capital and tourism features).

Tompkins and Adger (2004) stressed that the impact of, and coping responses to, shocksstresses (called short-term adaptiveness in VFSTD) depends on the accumulation of available social capital including the effectiveness of governance structures, levels of preparedness and the capacity to learn at the time of the shock's impact or the breaching of the stressor's tipping point. In VFSTD, this interaction is depicted by the arrow, which connects the exposure-sensitivity to short-term adaptiveness, in order to determine the subsequent utilisation of the available social capital and tourism - the immediate coping response to aid the reorganisation of the system in post-disaster events. The short-term adaptiveness then generates the long-term adaptiveness (social capital and tourism adjustment), which involve self-reflection, self-organisation, selflearning and the ability to consider any emerging opportunities for adjustment. The intervention or adjustment in this stage is crucial in fathoming future social capital and tourism vulnerability, which may lead to either positive or negative changes.

The addition of feedback in VFSTD indicates the 'transformation' or changes, and is based on the outcome of the actions, failed actions, or passivity in the short- and long-term adaptiveness response. These then disperse back into the system and decide the new levels of exposure and sensitivity to future destabilising events (Cunliffe, 2006). Notably, these actions can generate both positive and negative outcomes for different stakeholders or populations (McKercher, 1999). Calgaro et al. (2014) highlighted that interventions that address pre-existing weaknesses in the system would increase preparedness, social cohesion, learning and exchange, enhance access and entitlement to resources and redress power inequities. These factors may, in turn, decrease future exposure and sensitivity to shocks-stressors as well as enhance future adaptation. They also noted that a lack of adaptation, and/or failure of adaptive strategies, merely compounds exposure and sensitivity which can increase vulnerability levels. Feedback in TSVF is structurally presented by the back arrow, which indicates the positive, and/or negative feedback, which had been translated back into the system and determine new forms of vulnerability in the future. Importantly, this feedback may serve as a cornerstone towards tourism sustainability by ensuring stability and consistency of the system development cycle while facing the unstoppable hazards and changes. Besides that, the feedback also serves as the "turning point" that open up the integration of vulnerability approach into the sustainable tourism development as a system in the cycle.

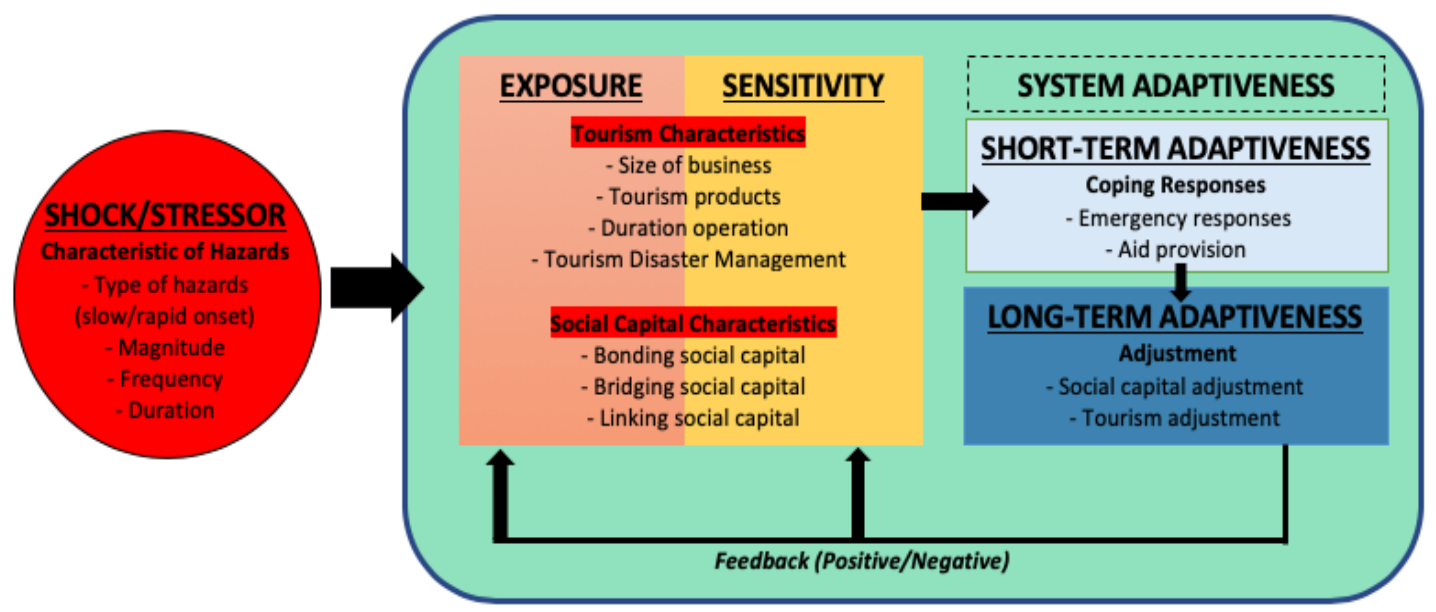

Figure 5. Vulnerability framework for sustainable tourism development (VFSTD) 


\section{Conclusion}

Across all the vulnerability frameworks in tourism context, this paper responds to the need for vulnerability analysis of tourism destinations to aid tourism sustainability especially for those destinations that face unavoidable or possible natural disasters. To capture the vulnerability analysis in the sustainable tourism context, Vulnerability Framework for Sustainable Tourism Development (VFSTD) is constructed as the core findings by adopting the Turner framework due to its coherent goals to encourage sustainability science through the vulnerability concept. VFSTD comprises four main elements, namely: (i) shocks-stressors, (ii) exposure, (iii) sensitivity and (iv) system adaptiveness. Importantly, the main features of Sources (tourism) and Power (social capital) are listed as the focal point for analysis, which influence each element in VFSTD. Importantly, both features of Sources and Power are contextualized as the human-environment interaction. Those elements are flexible and changeable to include the characteristics of the particular destination and population in each study. Particularly, users of VFSTD would able to explore the factors and processes that create and perpetuate vulnerability to natural disasters in tourism destinations, and elicit adjustment and feedback to encourage the tourism sustainability more holistically. This will bring more wide perspective to the planning as well as decision and policy making process of tourism development and its sustainability goal. Therefore, empirical evidents are required by applying the VFSTD in future tourism vulnerability analysis to acquire more information and findings for more fruitful application and significant of VFSTD.

\section{References}

Adger, W.N. (2006). Vulnerability. Global Environmental Change, 16(3), 268-81.

Agnitsch, K., Flora, J., \& Ryan, V. (2006). Bonding and bridging social capital: The interactive effects on community action. Community Development, 37(1), 36-51.

Aldrich, D.P., \& Meyer, M.A. (2015). Social capital and community resilience. American Behavioral Scientist, 59(2), 254-269.

Becken, S., Mahon, R., Rennie, H. G., \& Shakeela, A. (2014). The tourism disaster vulnerability framework: An application to tourism in small island destinations. Natural Hazards, 71(1), 955-972.

Bhandari, R.B. (2014). Social capital in disaster risk management: A case study of social capital mobilization following the 1934 Kathmandu Valley earthquake in Nepal. Disaster Prevention and Management, 23(4), 314-328.

Biggs, D. (2011). Understanding resilience in a vulnerable industry: The case of reef tourism in Australia. Ecology and Society, 16(1), 1-30.

Birkmann, J. (2006) Measuring vulnerability to promote disaster-resilient societies: Conceptual frameworks and definitions. In J. Birkmann, (ed.). Measuring vulnerability to natural hazards (pp. 9-54). Tokyo: United Nations University Press.

Blaikie, P.M., Cannon, T., Davis, I., \& Wisner, B. (1994). At Risk: Natural Hazards, People's Vulnerability, and Disasters. London: Routledge.

Brooks, N. (2003). Vulnerability, risk and adaptation: A conceptual framework. Tyndall centre for climate change. Working paper, 38(16).

Burton, I., Kates, R.W., \& White, G.F. (1978). The environment as hazard. Oxford: Oxford University Press. 
Calgaro, E., \& Lloyd, K. (2008). Sun, sea, sand and tsunami: Examining disaster vulnerability in the tourism community of Khao Lak, Thailand. Singapore Journal of Tropical Geography, 29, 288-306.

Calgaro, E., Lloyd, K., \& Dominey-Howes, D. (2014). From vulnerability to transformation: A framework for assessing the vulnerability and resilience of tourism destinations. Journal of Sustainable Tourism, 22(3), 341-360.

Clark, W.C., Jäger, J., Corell, R., Kasperson, R., McCarthy, J.J., Cash, D., \& Wilbanks, T.J. (2000). "Assessing Vulnerability to Global Environmental Risks." Report of the workshop on vulnerability to global environmental change: Challenges for research, assessment and decision making. May 22-25, 2000, Airlie House, Warrenton, Virginia. Cambridge, MA: Belfer Center for Science and International Affairs (BCSIA) Discussion Paper 2000-12, Environment and Natural Resources Program, Kennedy School of Government, Harvard University.

Cunliffe, S.K. (2006). Risk management for tourism: Origins and needs. Tourism Review International, 10(1-2), 27-38.

Cutter, S.L. (2003). The vulnerability of science and the science of vulnerability. Annals of the Association of American Geographers, 93(1), 1-12.

DFID. (1999). Social capital keysheet. Keysheets for Sustainable Livelihoods, (3), 1-2. Retrieved from http://www.keysheets.org/red_3_social_capital.html

Dredge, D., \& Jenkins, J. (2003). Destination place identity and regional tourism planning. Tourism Geographies, 5(4), 383-407.

Faulkner, B. (2001). Towards a framework for tourism disaster management. Tourism Management, 22,135-147.

Fukao, J. (2015). Community relocation and recreation of cultural environment. A case of Southern Indian region affected by the Indian Ocean Tsunami (In Japanese). In I. Hayashi, (ed.). Disaster reconstruction in the Asia Pacific nations. Humanitarian support, community relocation, disaster prevention and culture (pp. 117-139). Tokyo: Akashi Publishing.

Gallopin, G.C. (2006). Linkages between vulnerability, resilience, and adaptive capacity. Global Environment Change, 16, 293-303.

Guo, Y., Zhang, J., Zhang, Y., \& Zheng, C. (2018). Examining the relationship between social capital and community residents' perceived resilience in tourism destinations. Journal of Sustainable Tourism, 1-14.

Holling, C.S., \& Gunderson, L. (2002). Resilience and adaptive cycles. In L. Gunderson, \& C. S. Holling, (Eds.). Panarchy (pp. 25-62). Washington, DC: Island Press.

Howitt, R. (2001). Rethinking resource management: justice, sustainability and indigenous peoples. London: Routledge.

Hystad, P.W., \& Keller, P.C. (2008). Towards a destination tourism disaster management framework: Long-term lessons from a forest fire disaster. Tourism Management, 29,151162.

Innocenti, D., \& Albrito, P. (2011). Reducing the risks posed by natural hazards and climate change: The need for a participatory dialogue between the scientific community and policymakers. Environment Science Policy, 14(7), 730-733.

IPCC. (2007). Climate change impacts, adaptation and vulnerability. Working group II contribution to the IPCC fourth assessment report. 
Jodha, N.S. (1991). Mountain perspective and sustainability: A framework for development strategies. In M. Banskota, N.S. Jodha, \& U. Pratap, (Eds.). Sustainable Mountain Agriculture: Perspectives and Issues (pp. 41-82). New Delhi: Oxford IBH.

Kasperson, J.X. \& Kasperson, R.E. (2001). SEI Risk and Vulnerability Programme Report 2001-01. Stockholm: Stockholm Environment Institute.

Kasperson, J.X., Kasperson, R.E., Turner, B., Hsieh, W., \& Schiller, A. (2012). Vulnerability to global environmental change. In R.E. Kasperson, \& J. Kasperson, (Eds.). The Social Contours of Risk: Volume II: Risk Analysis, Corporations and the Globalization of Risk, (pp. 245-285). London: Routledge.

Kates, R.W. (1985). The interaction of climate and society. In R.W. Kates, J.H. Ausubel, \& M. Berberian, (Eds.). Climate impact assessment: Studies of the interaction of climate and society (SCOPE 27). New York: Wiley.

Kates, R.W., Clark, W.C., Corell, R.J., Hall, M., Jaeger, C.C., Lowe, I.,... Svedin, U. (2001). Sustainability science. Science, 292(5517), 641-642.

Kato, K. (2017). Debating sustainability in tourism development: Resilience, traditional knowledge and community: A post-disaster perspective. Tourism Planning \& Development, 1-13.

Le Masson V., \& Kelman, I. (2011). Disaster risk reduction on sovereign islands: La Re' union and Mayotte, France. Natural Hazards, 56:251-273.

McCarthy, J.J., Canziani, O.F., Leary, N., Dokken, D.J., \& White, K.S. (2001). Climate change 2001: Impacts, adaptation and vulnerability. Cambridge: Cambridge University Press.

McKercher, B. (1999). A chaos approach to tourism. Tourism Management, 20(4), 425-434.

Moser, C.O., Norton, A., Conway, T., Ferguson, C., \& Vizard, P. (2001). To Claim our rights: livelihood security, human rights and sustainable development. London: Overseas Development Institute.

Nelson, D.R., Adger, W.N., \& Brown, K. (2007). Adaptation to environmental change: Contributions of a resilience framework. Annual Review of Environment and Resources, 32(1), 395-419.

Nyaupane, G.P. \& Chhetri, N. (2009). Vulnerability to climate change of nature-based tourism in the Nepalese Himalayas. Tourism Geographies, 11(1), 95-119.

Orchiston, C. (2013). Tourism business preparedness, resilience and disaster planning in a region of high seismic risk: The case of the Southern Alps, New Zealand. Current Issues in Tourism, 16(5), 477-494.

Pelling, M. (2003). The Vulnerability of Cities: Natural Disasters and Social Resilience. London: Earthscan.

Poortinga, W. (2012). Community resilience and health: The role of bonding, bridging, and linking aspects of social capital. Health \& Place, 18(2), 286-295.

Prideaux, B. (2003). The need to use disaster planning frameworks to respond to major tourism disasters: Analysis of Australia's response to tourism disasters in 2001. Journal of Travel and Tourism Marketing, 15(4), 281-298.

Putnam, R. (2000). Bowling alone: The collapse and revival of American community. New York: Simon \& Schuster.

Raven, P.H. (2002). Science, sustainability and the human prospect. Science, 297, 954-958.

Ritchie, B.W. (2008). Tourism disaster planning and management: From response and recovery to reduction and readiness. Current Issues in Tourism, 11(4), 315-348. 
Ruiu, M.L., Seddaiu, G., \& Roggero, P.P. (2017). Developing adaptive responses to contextual changes for sustainable agricultural management: The role of social capital in the Arborea district (Sardinia, Italy). Journal of Rural Studies, 49, 162-170.

Sanyal, S., \& Routray, J.K. (2016). Social capital for disaster risk reduction and management with empirical evidences from Sundarbans of India. International Journal of Disaster Risk Reduction, 19, 101-111.

Scott, N., Laws, E., \& Prideaux, B. (2008). Tourism Crises and Marketing Recovery Strategies. Journal of Travel \& Tourism Marketing, 23(2), 1-13.

Simpson, M.C., \& Gladin, E. (2008). Good practices: Natural hazard risk management in the Caribbean tourism sector Carribbean Regional Sustainable Tourism Development Programme (CRSTDP). Barbados, Caribbean Tourism Organization.

Smit, B., \& Wandel, J. (2006). Adaptation, adaptive capacity and vulnerability. Global Environment Change, 16, 282-292.

Sutherland, R., Eberhart-Phillips, D., Harris, R.A., Stern, T., Beavan, J., \& Ellis, S. (2007). Do great earthquakes occur on the Alpine Fault in central South Island, New Zealand? Geophysical Monograph, SIGHT 175, 235-251

Szreter, S., \& Woolcock, M. (2004). Health by association? Social capital, social theory, and the political economy of public health. International Journal of Epidemiology, 33(4), 650667.

Tompkins, E.L., \& Adger, W.N. (2004). Does adaptive management of natural resources enhance resilience to climate change? Ecology and Society, 9(2), 10.

Tsai, C.H. \& Chen, C.W. (2010). An earthquake disaster management mechanism based on risk assessment information for the tourism industry-a case study from the island of Taiwan. Tourism management, 31, 470-481.

Tsao, C.Y., \& Ni, C.C. (2016). Vulnerability, resilience, and the adaptive cycle in a crisis-prone tourism community, Tourism Geographies, 18(1), 80-105.

Turner, B.L., Kasperson, R.E., Matson, P.A., McCarthy, J.J., Corell, R.W., Christensen, L.,...Schiller, A. (2003). A framework for vulnerability analysis in sustainability science. Proceedings of the National Academy of Sciences of the United States, 100 (4), 8074079.

UNISDR. (2012). Terminology. Retrieved from http://www.unisdr.org/we/inform/ terminology\#letter-V

UNWTO. (2018). International Tourists Arrival 2017. Retrieved from http://media.unwto.org/press-release/2018-01-15/2017-international-tourism-results highest-seven-years

Vogel, C., \& O'Brien, K. (2004). Vulnerability and global environmental change: Rhetoric and reality. AVISO - Informational Bulletin on Global Environmental Change and Human Security, 13(3), 1-8.

Wisner, B., Blaikie, P., Cannon, T., \& Davis, I. (2004). At risk: Natural hazards, people's vulnerability and disasters. London: Routledge.

Yusuf, A.A., \& Francisco, H. (2009). Climate Change Vulnerability Mapping for Southeast Asia. Economy and Environment Program for Southeast Asia (EEPSEA), revised Jan 2009. 